Derecho y Realidad

Vol.13 - Núm. 26 • Julio-Diciembre de 2015

Págs. 265-300. ISSN:1692-3936

\title{
EI derecho a la vivienda digna para la población desplazada víctima del conflicto armado colombiano, residente en Tunja*
}

\section{The right to decent housing for the I DPs victims of the Colombian armed conflict, that live on Tunja}

Mauricio Reyes Camargo**

\section{Resumen}

El desplazamiento forzado se ha convertido en Colombia en uno de los problemas sociales de mayor connotación, que amerita atención por las múltiples consecuencias que se derivan de las omisiones presentadas. Por tal motivo se requirió investigar las políticas públicas desarrolladas por el municipio de Tunja, en lo que respecta a la satisfacción del derecho fundamental a la vivienda digna de la población desplazada víctima del conflicto armado. Investigación que estuvo sustentada en los planteamientos establecidos en la sentencia T-025 de 2004, de la Corte Constitucional, que sienta un precedente jurisprudencial con fundamento en los antecedentes

Fecha de aceptación: 16 de septiembre de 2015

Concepto de recepción: 27 de septiembre de 2015

Fecha de aprobación: 23 de octubre de 2015

\footnotetext{
* Este articuo ha sido desarrollado cn fuendmaneto en mi experiencia como concejal de la ciudad tunja y las notables necesidades del muicipio y su población, victima del conflicto armado.

* Abogado, especialista en Derecho Administrativo y Contratación Pública, estudiante de Maestría en Derechos Humanos en la Universidad Pedagógica y Tecnológica de Colombia de Tunja. mauricioreyesc.23@hotmail.com
} 
generados en este campo y con las sentencias unificadas posteriores, al igual que con el seguimiento continuo que se le ha dado a dicho problema a nivel nacional, en aquellos departamentos y municipios con mayor presencia de desplazados, donde ni el departamento de Boyacá y menos el municipio de Tunja, aparecen en las estadísticas nacionales como centros receptores de población desplazada, pese a que según estadísticas de la Personería Municipal de Tunja, son aproximadamente 500 familias. No obstante los múltiples autos de seguimiento a la sentencia T-025 de 2004, la situación de los desplazados en materia de otorgamiento de vivienda como derecho fundamental, sigue siendo pésima en el caso de la población residente en Tunja, por la forma tan burda como el Estado a través de sus diversas dependencias, les rapó las 99 oportunidades de vivienda, al mismo número de familias. Valga decir que, en este caso, el municipio es el responsable de este atropello.

\section{Palabras clave}

Derechos fundamentales, desarticulación, desactualización, exclusión, irresponsabilidad, miseria, omisión, rechazo, caos.

\section{Abstract}

Forced displacement has become Colombia in one of the social problems of highest connotation that deserves attention for the multiple consequences due to omissions. For this reason it was required to investigate public policies developed by the municipality of Tunja, with regard to the satisfaction of the fundamental right to decent housing of the displaced victims of the armed conflict. This research was sustained in the approaches set out in the sentence T-025 of 2004, of the Constitutional Court, that sets a precedent based on the records generated in this field and with the subsequent unified sentences, as with continuous monitoring that has been given to this problem at the national level in those departments and municipalities with high presence of displaced people, where neither the department of Boyacá, nor the city of Tunja, appear in national statistics as recipients centers of displaced population, however, according to statistics from the Municipal Attorney of Tunja, are about 500 families. Despite the above and the multiplicity of court orders in pursuance of Sentence T-025 of 2004, the situation of the displaced people related to housing as a fundamental right, in the case of the resident 
population in Tunja, remains very bad by the way so crude as the State through its various agencies, stole them 99 housing opportunities to the same number of families. It is worth to say that, in this case, the municipality is the responsible of this outrage.

\section{Keywords}

Chaos, fundamental rights, dismantling, outdated, exclusion, irresponsibility, poverty, failure, rejection.

\section{Sumario}

Desarrollo de la pregunta de investigación, conclusiones y recomendaciones.

\section{Método}

Jurídico estadístico.

\section{Metodología}

Se pretende determinar la responsabilidad de la alcaldía de tunja en el accesos a la vivienda para la población desplazada y en condicion de vulenrabilidad. 


\section{Introducción}

El objetivo de esta investigación fue realizar un estudio sobre el derecho a la vivienda digna para la población desplazada víctima del conflicto armado colombiano, residente en Tunja, con el fin de analizar el amparo que debe brindársele dadas las condiciones que afronta por parte del Estado. En ese orden de ideas, se relacionan los correspondientes referentes teóricos que incluyen lo pertinente al derecho fundamental a la vivienda digna para estas personas (legislación internacional y nacional); se tienen en cuenta las políticas públicas, aplicables al derecho fundamental a la vivienda digna de dichas familias. Para ello se analizan los documentos Conpes y los planes de desarrollo (nacional y municipal) y las teorías humanísticas y críticas de los derechos humanos relacionadas con el eje de la investigación. También se verifica si las preguntas expresadas en la formulación del problema se cumplen, a través del diagnóstico realizado con las familias desplazadas, detallando su situación actual, con fundamento en la jurisprudencia colombiana, y por último, se presentan las conclusiones y recomendaciones.

Respecto a los estudios previos realizados sobre el eje temático, la Defensoría del Pueblo,

basada en datos de la Unidad Para la Atención y Reparación Integral a las Víctimas (Uariv), el 48,1 \% de los desplazados en Colombia por el conflicto armado se encuentran en los departamentos de la región Pacífica. De esta forma, hasta el 2013 se habían contabilizado 18.167 desplazados en Nariño; 17.468 en el Valle del Cauca; 12.156 en el Cauca y 7.736 en el Chocó. La Defensoría agrega que «el 47,7 por ciento de los desplazados pertenecen a comunidades negras y el 23, 9 por ciento a comunidades indígenas». El informe también indica que de la «lista de 25 municipios con mayor desplazamiento en el país, doce hacen parte de estos cuatro departamentos: Buenaventura y Cali (Valle del Cauca); Tumaco (Nariño); Quibdó, Litoral de San Juan, Riosucio y Bajo Baudó (Chocó); Suárez, López de Micay, Argelia, Timbiquí, El Tambo y Bolívar (Cauca). (Defensoría del Pueblo, 2013, p. 2)

Si se retoman las cifras anteriores y se confrontan con las que se relacionan a continuación, la diferencia es abismal, siendo más aproximada a la realidad, la de la Contraloría General de la República.

En Colombia, la Corte Constitucional es la encargada de seguir el accionar del Estado sobre los desplazados víctimas del conflicto interno, para darle cumplimiento a la sentencia T-025 de 2004, responsabilidad que le corresponde asumir al Gobierno (Corte Constitucional, 2015). 
De las encuestas aplicadas, producto de la sentencia T-025 de 2004, para conocer las cifras y situación de los desplazados en el país, la primera fue de la Contraloría General de la República: la Encuesta Nacional de Víctimas, que reveló que las metas establecidas en los Conpes 3712 de 2011 y 3726 de 2012, «están rebasadas, ya que el universo del total de personas desplazadas de manera forzada, que se tenía hasta el 2011, era de 3,8 millones y hoy en día es de 5,6 millones» (Defensoría del Pueblo, 2013, p. 19). El Gobierno, por su parte, en sus reportes actuales afirma que son

6 millones de personas desplazadas por la violencia y un millón de personas afectadas por otros hechos victimizantes. Concluyó la Contraloría que el 11,9 por ciento de la población total del país es desplazada. A su vez alertó por el aumento en el despojo de tierras, en 7 millones 73 mil hectáreas, un incremento de 435.000 entre 2010 y 2013. (Defensoría del Pueblo, 2013, p. 21)

En las dos cifras existe una diferencia de más de 400.000 desplazados, por lo que la Contraloría le solicitó al Gobierno utilizar métodos o parámetros de medición que sean más próximos a la realidad y, a la vez, reiteró que los recursos han sido y son insuficientes para atender adecuadamente este problema humanitario como lo exige la sentencia T-025 de 2004.

De igual manera, el Dane (2014), a través de la Encuesta de Indicadores de Goce Efectivo de Derechos, en la medición realizada afirma que la población desplazada por el conflicto armado, es cada vez mayor y que el Estado colombiano ha hecho esfuerzos importantes para brindarles atención. Sin embargo, esta muestra la efectividad y continuidad que debe prestárseles, porque las políticas públicas diseñadas y aplicadas se fundamentaron en cifras correspondientes al año 2010, lo que indica por tanto un desfase importante respecto a la realidad vigente.

En el mismo sentido, la Unidad de Víctimas, afirma que «el Gobierno ha cumplido en un 97 por ciento el registro a las víctimas, y ha hecho un esfuerzo con la Ley 1448 que se empezó a aplicar en 2012, y que le ha restablecido los derechos a los afectados. Pero reconocemos que hay muchos retos» (Defensoría del Pueblo, 2013, p. 43). En este caso, el Estado reconoce que presenta un margen de error en sus cifras de desplazados por el conflicto armado de 3,0\%, avanzando en la atención, pero los esfuerzos no se concretan mientras no se les garantice el cumplimiento de los derechos fundamentales respecto a todas sus necesidades, especialmente en lo atinente a la vivienda.

Para la Contraloría,

La población víctima del desplazamiento en estado de indigencia es del 35,5 por ciento, y la población desplazada menor o igual a la línea de la pobreza 
Ilega al 80 por ciento. Mientras que la encuesta de la Unidad de Víctimas habla de que el 33 por ciento (en 2010 era del 77 por ciento) de los hogares víctimas del desplazamiento está en situación de miseria, y el 63,8 por ciento en la pobreza (en 2010 era del 97 por ciento). (Citada por la Defensoría del Pueblo, 2013, p. 49)

Además de mostrar las cifras una diferencia de 17 puntos en lo relacionado con la pobreza, estas son muy dicientes y contradicen lo que afirman representantes del Gobierno, que maquillan los resultados para minimizar este grave problema.

\section{Desarrollo de la pregunta de investigación}

Partiendo del hecho que las políticas públicas y la normatividad (internacional y nacional) son instrumentos del Estado, que le permiten garantizar los derechos humanos de los desplazados colombianos por causa del conflicto interno, y brindarles las garantías que requieren, incluyendo el suministro de vivienda digna, a fin de proteger su integridad y la de los miembros de sus familias, es posible afirmar que a nivel nacional las políticas y el ordenamiento jurídico no han sido del todo funcionales. En ese orden de ideas, surgen los siguientes interrogantes: ¿En qué forma las políticas públicas y la normatividad vigentes en Colombia y en el municipio de Tunja como herramientas que se orientan a garantizar los derechos humanos a los desplazados por el conflicto armado colombiano, les brindan una vivienda digna a los integrantes del núcleo bajo principios humanistas? ¿Qué incidencia tiene en la población desplazada residente en Tunja, la flagrante violación del derecho fundamental a una vivienda digna?

La Ley 387 de 1997, los decretos y resoluciones que se refieren a la atención a la población desplazada víctima del conflicto armado colombiano, determinan la intervención de las autoridades municipales en tres grandes momentos: prevención, atención humanitaria y estabilización económica. En el primero, o sea en el de prevención, no aplicaría en el presente caso en Tunja, porque se trata de analizar los hechos o causas que provocan el desplazamiento y en lo posible buscar que esto se genere a través de profesionales especializados que trabajan como grupo de apoyo. En el segundo, que se refiere a la atención humanitaria de emergencia, corresponde a los comités locales e instituciones centrales del Estado, suministrarle a la población desplazada

alimentos, alojamiento y servicios médicos, entre otros, durante los primeros tres meses del desplazamiento, prorrogables según la valoración de las necesidades de los hogares desplazados. En esta etapa, AS es la entidad responsable de la financiación de los programas, pero no de su funcionamiento. La implementación de los programas de asistencia humanitaria de emergencia 
está a cargo de los operadores en conjunto con las autoridades locales (Ibáñez \& Moya, 2007, p. 23).

EI tercero corresponde a la estabilización socioeconómica, donde se ha de

garantizar que la población desplazada sea capaz de velar por su sostenimiento económico ya sea en el municipio de origen (retorno) o en cualquier otro municipio (reubicación). La superación de la pobreza y del estado de vulnerabilidad ocasionado por le pérdida de activos y el desplazamiento depende de la capacidad de generación de ingresos por parte de la población desplazada de manera independiente y no por políticas basadas en la asistencia humanitaria. El objetivo de la etapa de estabilización económica es alcanzar la recuperación de la capacidad productiva de las víctimas del desplazamiento, a través de programas de generación de ingresos, provisión de créditos, asistencia técnica, educación, atención en salud, vivienda, capacitación técnica y la asignación de tierras. Las instituciones del Gobierno Nacional encargadas de esta fase son INCODER, el Ministerio de Agricultura y Desarrollo Rural, Acción Social, SENA, el Ministerio de Educación, el Ministerio de Vivienda y Ambiental y el Ministerio de Protección Social. Las responsabilidades de ejecución de la política de estabilización socioeconómica, si bien están definidas en la legislación, no son claras para el caso de las autoridades. (Ibáñez \& Moya, 2007, p. 35).

En el cumplimiento de los momentos citados, pareciera que la existencia de siete Conpes aprobados en el período 1995-2013, fuesen suficientes para atender la creciente, difícil y grave problemática de la población desplazada y sus necesidades de vivienda, sin embargo, la dicotomía y multiplicidad de funciones repetitivas o encontradas en las diversas entidades hacen que el aparato estatal no sea funcional, lo que conlleva a cuestionar las acciones emprendidas hasta ahora como se observará en capítulos posteriores.

Por otra parte, el Plan Nacional de Desarrollo 2010-2014, denominado «Prosperidad para todos», título bastante Ilamativo que hace soñar momentáneamente a toda persona que lo lea o escuche, porque genera expectativas de gran visión para todos los colombianos, especialmente los más necesitados y sobre todo desplazados, quienes han tenido que enfrentar, superar y vencer en cierta forma las acciones abusivas de los actores armados, y por otra, enfrentar las acciones paquidérmicas del Estado, que contradicen el título del mismo. Así mismo, las medidas de protección y prevención del desplazamiento citadas en el aparte anterior, son bastante ambiciosas, porque después de más de 80 años de conflicto armado en Colombia, donde los actores que actúan como victimarios son cada vez más numerosos y 
sofisticados en sus armamentos y métodos de sometimiento, razón por la cual una propuesta de estas, de tanta importancia, no puede quedarse relegada en el tiempo.

Al retomar los contenidos de los documentos Conpes y Plan de Desarrollo «Prosperidad para todos» en lo que corresponde a la atención a la población desplazada, Ilama la atención las exigencias en la coordinación que debe existir entre las entidades del orden nacional, luego de la nación a las entidades territoriales y por último, entre entidades territoriales, sin embargo, es allí donde se observa el mayor caos y un ejemplo de ello, se observa en la responsabilidad que le corresponde a algunos de los entes locales para caracterizar a la población de la referencia, donde la Personería Municipal, la Unidad de Atención a las Víctimas, la Defensoría del Pueblo y la Secretaría de Protección Social, eluden su responsabilidad, cada una sin ningún argumento válido.

En el tratamiento de la teoría crítica de los derechos humanos y su impacto en la violación al derecho fundamental a una vivienda digna, es necesario retomar la historia de Colombia, especialmente en lo que se refiere a la conquista española. Al respecto, Sarmiento Anzola afirma que

la barbarie de la invasión española en el actual territorio colombiano dejó profundas raíces en su modelo de acumulación, caracterizado por la expoliación de la naturaleza y la explotación y opresión de la fuerza de trabajo mediante la hacienda esclavista y la extracción minera...Cinco siglos después, este modo de producción se reedita con la misma barbarie y ahora bajo el dominio de transnacionales financieras y mineras. (2012, p. 123)

En los inicios de la «época hispánica», como la denominan algunos eruditos en materia de historia, cabe destacar la «conquista» donde la presencia de los signos dominantes de la misma fueron el hombre, el caballo, la espada y por último, la cruz, que fue el que menos daño hizo en términos peyorativos. Cabría preguntarse qué conquistaban y por qué. Sin embargo, la afirmación de Sarmiento Anzola da las correspondientes respuestas, porque los conquistadores no solo se Ilevaron las riquezas, sino que utilizando la barbarie de esa época sometieron a los conquistados a la esclavitud, mientras que esquilmaban los recursos existentes.

En el ambiente globalizado de hoy, la barbarie se ha sofisticado y modernizado utilizando métodos, herramientas e ideas que superan todas las expectativas de las técnicas de guerra utilizadas en otros países y continentes, porque a diferencia de un solo Estado conquistador, ahora son muchos los que hacen presencia a través de transnacionales que con la connivencia del Estado, sus fuerzas y de las alianzas maquiavélicas que realizan con políticos, guerrilleros, paramilitares y delincuencia 
común, cometen todo tipo de atrocidades, sin excluir el deterioro ambiental, el detrimento que en esta materia se causa al ecosistema y al futuro de las próximas generaciones. Ellos, además de los lucros anteriores, obtienen grandes exenciones, no solo en materia tributaria, sino también en lo que respecta a lo judicial, pues son inmunes a cualquier tipo de enjuiciamiento, por el blindaje que les otorga el Estado, porque son gestores de un «desarrollo», pero a la inversa.

Continuando con el ambiente de conquista y de beligerancia que predomina en Colombia, Sarmiento reafirma lo expuesto y se torna más agravante cuando dice que

en las zonas rurales la población lleva la peor parte del enfrentamiento bélico, y como producto del destierro y la expropiación, asociados a la guerra, se profundiza la consolidación de poderes regionales-paramilitares, la presencia directa de empresas transnacionales y la invasión de tropas estadounidenses y la pérdida progresiva de ingresos de los pobres del campo. (Sarmiento, 2012, p. 135)

En ese orden de ideas, con la inserción y el ensanchamiento de grandes extensiones de cultivos dedicados al cultivo de la palma africana y otros, desde la pequeña hasta la mediana propiedad, están siendo apetecidas por el interés desbordado del capital extranjero y de los grandes terratenientes y empresarios colombianos, como se observa en las seis grandes haciendas de propiedad ancestral de los indígenas que están siendo usurpadas por el Estado a través de la fuerza pública y de las acciones ilegales y non sanctas de los dueños del poder, cuyo ejemplo que vale destacar es la masacre de EI Nilo y el asentamiento indígena, donde el accionar abusivo de Estado, transnacionales y empresarios no ha tenido la divulgación y connotación en los medios de comunicación de propiedad de los grandes pulpos económicos colombianos y menos que a ellos los defiendan instancias que están en obligación de hacerlo, como la Defensoría del Pueblo, personerías y Procuraduría.

Es por ello que el sector rural colombiano está cada vez más postrado, ante el avatar de las fuerzas conquistadoras de la época, unidas al accionar de los diferentes actores al margen de la ley y de las fuerzas del Estado, que son responsables de su defensa según la Constitución de 1991. Pues estas fuerzas están generando el terror en el campo y el desplazamiento masivo hacia las ciudades, especialmente hacia las capitales de departamento, donde los campesinos sufren todo tipo de atropellos y avasallamiento, porque ingresan a las filas de los cinturones de miseria. Como lo expresa Reyes Posada, «en general, la violencia del conflicto armado y del narcotráfico ha empeorado la inequidad en las regiones más afectadas y, lo que es más grave, ha deteriorado los medios democráticos para expresar y resolver los conflictos sociales» (2012, p. 365). 
En ese ambiente de violencia y abusos en contra de los más necesitados, el Estado se ha visto obligado a tomar medidas porque los indígenas abanderados destacados de esta lucha que cada vez merma sus fuerzas con el asesinato de líderes ha logrado a través de sentencias de la Corte Constitucional, Consejo de Estado y de la Corte Interamericana de Derechos Humanos, sentar jurisprudencia para defenderse de los múltiples abusos comunes de las fuerzas del orden y de las que están al margen de la ley, para defender sus territorios ancestrales y defender sus derechos fundamentales, incluyendo el sitio donde residen desde la colonia. Dicho problema lo reconoce y analiza Sarmiento Anzola, cuando afirma que

El problema de la propiedad y el acceso a la tierra constituyen actualmente el centro de los debates políticos nacionales. El gobierno reconoce la gravedad de los problemas asociados a la tierra: i) destierro y despojo; ii) relaciones entre narcotráfico, paramilitarismo, terratenientes y concentración de la propiedad; iii) complicidad de agentes del Estado; iv) los efectos del cambio climático agravan la crisis agraria; v) la relación entre cambios climáticos, catástrofes naturales e inseguridad alimentaria. (2012, p. 140)

El Estado, al menos, reconoce mínimamente la problemática que afecta a los colombianos residentes en zonas rurales, especialmente en aquellas donde están ubicadas las principales riquezas (petrolera y minera). Sin embargo, no toma medidas radicales para acabar con los múltiples flagelos existentes y al contrario, sugiere paños de agua tibia, que en vez de alcanzar soluciones, agrava los problemas. En este sentido, afirma Sarmiento (2012, p. 140): «actualmente, la economía colombiana se caracteriza por su mineralización, financiarización, transnacionalización, concentración y uso de la violencia como fuerza productiva y como recurso de la reproducción del poder». Porque solo a una minoría de desplazados se ha logrado restituir sus predios despojados, frente a un gran número de reclamantes que están siendo asesinados.

Por su parte, Cristo reconoce que

con la ley 1448 de 2011 o Ley de Victimas de Restitución de Tierras, el Estado colombiano asume el desafió de restituir los predios despojados y beneficiar a cerca de cinco millones de campesinos desplazados violentamente durante las dos últimas décadas...y la creación de nuevas entidades al interior del Estado dedicadas en forma exclusiva a la atención de las víctimas, entre otras medidas que son la cuota inicial para la reconciliación nacional. (Cristo, 2012, p. 216)

Cuando se habla de la restitución de tierras despojadas en Colombia, en análisis que se hacía en el Congreso colombiano según los pírricos avances que se han 
logrado hasta ahora y calculando que falta por decidir en más de 360.000 reclamaciones que corresponden a 6.000 .000 de hectáreas, sólo hasta el año 2.515 se podrían decidir estas o sea dentro de 500 años ${ }^{1}$.

En esas reclamaciones entre la diversidad de barbarie que ha vivido el país, especialmente los que menos tienen, Cristo reconoce que, «El compromiso nacional implica también la protección y respeto de los 756 resguardos indígenas y los 166 territorios colectivos de comunidades afrodescendientes»(2012, p. 217). Sin embargo, este es uno de los pactos que más disparidad representa, porque son las extensiones más grandes del territorio colombiano que están siendo usurpadas, a pesar de la lucha unificada que han adelantado los indígenas.

En cuanto a la protección prometida por el Estado en Colombia, Restrepo afirma que,

el régimen de Uribe Vélez ofreció la idea de pacificar el país, no para vivir mejor, sino para ganar la confianza de los inversionistas, para quienes no son ajenos los informes sobre la barbarie causada durante tal proceso de pacificación, los mismos que hoy disfrutan las utilidades y una rentabilidad del 100,0 \% de sus inversiones; es cierto que la economía crece, pero el desempleo, la desigualdad, la pobreza, la delincuencia, las violencias de mantienen. (2012a, p. 53)

Se observa en el comentario anterior que las cifras son contradictorias: mayor riqueza y beneficios económicos para una minoría, especialmente extranjera, y una creciente desigualdad y empobrecimiento para más de 6.000 .000 de colombianos que han sido desplazados de sus propiedades y territorios, Ilevándolos con la ruptura de sus familias, trabajo y sostén económico a un ambiente de incertidumbre, que hasta ahora el Estado, a pesar de sus múltiples promesas escritas, no ha podido cumplir, porque existen intereses ocultos donde esa mano tenebrosa y siniestra hace presencia para seguir masacrando y acallando a los líderes que se atreven a protestar.

\footnotetext{
Restitución de tierras. Disponible en: http://www.elespectador.com/noticias/politica/colombia-senecesitarian-mas-de-500-anos-acabar-restitu-articulo-556232 (21 de abril de 2015). 72.623 solicitudes radicadas al 30 de diciembre de 2014 . No es más del $20 \%$ de la meta de la ley: se esperaban 360.000 en 10 años. El 10 de junio de 2021 vence el plazo para radicar solicitudes de restitución. Ya llevamos 4 años. A junio de 2014, había 965 sentencias restitutivas, de las cuales 946 estaban mal: a) 74 sentencias sin delimitar la tierra; b) 418 sentencias fallaron un área mayor a la real y c) 424 sentencias fallaron un área menor a la real. A marzo de 2015, hay 1041 sentencias restitutivas, que devuelven 94.156 hectáreas de tierra. Para lograr la meta y entregar las 6.000 .000 hectáreas que se calculan fueron despojadas violentamente, la Unidad de Restitución de Tierras tendría que devolver 984.307 hectáreas por año
} 
En el mismo sentido, Restrepo expresa que,

las trasnacionales no podrían ocupar las zonas de riqueza natural y energética en los países del Sur de los que toman Ias riquezas y dejan miseria y regalías, sin el apoyo de ejércitos ilegales al servicio del capital en alianza o cooperación con fuerzas militares legales cubiertas, además con las garantías jurídicas, para aplicar tácticas de guerra en defensa de la acumulación económica. (2012b)

Esas afirmaciones de Restrepo muestran, como se dijo anteriormente, que existe un contubernio malévolo entre el Estado colombiano, sus fuerzas del orden con las transnacionales y grupos económicos nacionales, para desestabilizar y atacar al que menos tiene que reside en el sector rural, lo cual se agrava cuando se amangualan según la conveniencia con paramilitares, guerrilleros, delincuencia común o bandas criminales, generando miles de muertos que a pesar de la ley del mínimo esfuerzo que ejerce el Estado, nunca encuentra a los responsables, porque se incumplen los derechos fundamentales contenidos en la Constitución de Colombia de 1991, sin citar la nutrida jurisprudencia nacional y la internacional, que actúan como letra muerta.

Para Restrepo, «La barbarie es la resultante de una cadena en cuya cabeza están el capital y el poder, y en la cola, la degradación provocada por una violencia sin límites que difícilmente puede explicar la razón» $\left(2012^{a}\right.$, p. 57). Afirmación que coincide con lo expuesto anteriormente, porque en esa fila faltan los principales personajes, porque los siniestros ya están identificados, y son los desplazados, colombianos del común que en la realidad no están amparados por el Estado y su oligarquía. Aunque es inverosímil que un monstruo surgido del esquilamiento que a lo largo de los años ellos con sus partidos políticos y familias completas, han consolidado un emporio mafioso, que se ha enriquecido y afianzado en el poder.

Para colmo de males y con el fin de maquillar la barbarie que han cometido por más de 500 años en el país, surgen como salvadores y defensores de las víctimas de la guerra (desplazados) que ellos mismos han creado, sofisticado y engendrado entregando pírricas sumas por el daño causado, después de largos y tediosos procesos en el paquidérmico sistema judicial colombiano, que tardan más de quince años en pronunciarse, tiempo durante el cual los reclamantes han perdido la vida. Como lo afirma Restrepo, «los Estados han convertido en usual la práctica de sostener un rubro del presupuesto para indemnizar económicamente a una pequeña parte de sus víctimas permanentes» $\left(2012^{a}\right.$, p. 60). Es así como Restrepo aduce que, «en particular, en América Latina la barbarie aprendida fue potenciada con la implementación de ajustes a la crueldad, que en Colombia supera toda ficción sobre lo que puede significar la deshumanización. Los responsables: el capital y el poder, manifiestos en la connivencia entre la clase política, los militares y los empresarios» $\left(2012^{a}\right.$, p. 64). 
Nuevamente surge el término de barbarie, con las correspondientes consecuencias y su concepción, pero realmente es difícil definirla, cuando se retoman y analizan diversos y múltiples casos ocurridos en el país, en los cuales los más afectados han sido las mujeres y los niños inocentes, a los cuales se les trató sin el mínimo miramiento de su condición indefensa, que con el escaso apoyo de grupos interdisciplinarios donde se encuentran desplazados, porque son muchos los municipios y ciudades por donde todavía transitan, buscando una respuesta y soluciones para sus diversas dificultades ante un Estado indolente y unas instancias en las mismas condiciones. En ese orden de ideas, Restrepo afirma que esta es «una barbarie que cambió la estética, eliminó la ética y la política, fortaleció la corrupción política y la impunidad y transformó las emociones y los valores de todo un país que quedó suspendido y fuera de sí mismo, perdió la capacidad de asombrarse, de hablar y de vivir la realidad en tiempo presente» $\left(2012^{a}\right.$, p. 70).

La barbarie descrita se inicia con la decapitación, la violación de niñas y mujeres indefensas y el asesinato de sus progenitores en la guerra fratricida entre partidos políticos; luego fueron mejorando sus técnicas con el empalamiento, las motosierras para descuartizar, la utilización de lagos llenos de caimanes para desaparecer a las víctimas enemigas, el incendio de las viviendas con sus residentes en el interior, el uso de hornos para la quema de ladrillos para no dejar huella alguna de los asesinados.

Como se puede observar, la barbarie tiene una mayor dimensión y connotación, cuando muchos de estos crímenes de realizaron en presencia de los niños, para que aprendieran la lección: no ser enemigos de los opresores y porque además habían cometido múltiples errores, haber nacido en un país cuyas autoridades se convierten en sus persecutoras, solo por ser pobres y porque supuestamente estaban conformando la ilegalidad. Si se mira la historia del mundo, los colombianos gestores de la guerra y actores de reparto como justicieros de la misma, no excluyeron ninguna enseñanza. Ni siquiera, la de los campos de concentración alemanes, antes por el contrario perfeccionaron sus prácticas, olvidándose del alicate saca uñas y reemplazándolo por la motosierra para la apertura de vientres.

De los desplazados de la referencia anterior, también han llegado muchos de ellos a la ciudad de Tunja, donde no existen estadísticas o estudios que muestren cuál ha sido la tendencia del desplazamiento urbano en esta ciudad, con sus características. En la búsqueda realizada, se comprobó que este problema humanitario se reflejaba desde el año 2000, donde hacían presencia aproximadamente 152 (50 familias aproximadamente) personas provenientes de diferentes regiones de Colombia. A partir de esa fecha, solo hasta el año 2012 se encuentran datos de estas personas en la Personería de Tunja y en la Secretaría de la Mujer, Equidad de Género y Desarrollo Social. Sin embargo, estos muestran diferencias sustanciales en el número de personas, familias, integrantes por género, procedencia (por departamento) y barrio 
donde se encuentran ubicados. Respecto al número de familias desplazadas de otras regiones colombianas por culpa de la violencia que se vive en el país, en el año 2012 eran 90 y al 2014, ascendían a 163, para un total de 408 observándose un incremento de 318 , que equivalen a un 353,3 \% (ver Tabla 1, Figura 1).

En cuanto a los integrantes, en el primer año eran 400 y en el último 1.017, para un total de 2.089 personas, aumentándose en 1689, lo que representa un 422,2\%. En el total de la referencia, las mujeres representan un $52,7 \%(1.108)$ y los hombres el $47,3 \%$ (981). La tendencia en ambos casos es al aumento y lo mismo ocurre con el número de familias y de sus integrantes, convirtiéndose este en un nuevo y grave problema para la administración de Tunja, porque los niveles de desplazamiento (receptora) son bajos frente a otros municipios que se han caracterizado por ser los más representativos.

En cuanto a la caracterización por edades de la población víctima del conflicto armado residente en Tunja a 2014, 627 son menores de trece años (30,0\%); 835 $(40,0 \%)$ personas se ubican en el rango entre 13 a 26 años y $627(30,0 \%)$ son mayores de 60 años (ver Tabla 2, Figura 2). La tendencia en los seis rangos de edad, es creciente en los tres años.

Respecto a la distribución total de los desplazados por edades, la mayor participación está en los adultos con 627 (30,0\%), siguiéndole los adolescentes con 422 (20,0 $\%)$, juventud $413(20,0 \%)$, primera infancia 337 (16,0\%) e infancia con 290 $(14,0 \%)$ (ver Figura 3).

Entre las víctimas del desplazamiento residentes en Tunja de 2.089 personas, 141 $(6,7 \%)$ se encuentran en condiciones de discapacidad. De ese total 93 son mujeres $(65,9 \%)$ y 48 son hombres (34,1\%). En el primer caso, 89 (96,0\%) se ubica en los rangos de edad de 18 a 60 años y en el segundo, la mayor concentración de 44 (92,0 \%) está entre los 27 a más de 60 años de edad (ver Tabla 3, Figura 8).

Tabla 1. Familias desplazadas residentes en Tunja (septiembre de 2014)

\begin{tabular}{|c|c|c|c|c|c|c|c|c|}
\hline Año & $\begin{array}{c}\text { Número } \\
\text { familias }\end{array}$ & $\mathbf{\%}$ & Integrantes & $\mathbf{\%}$ & Mujeres & $\mathbf{\%}$ & Hombres & \% \\
\hline 2012 & 90 & 22,0 & 400 & 19,0 & 213 & 19,0 & 187 & 19,0 \\
2013 & 155 & 38,0 & 672 & 32,0 & 332 & 30,0 & 340 & 35,0 \\
2014 & 163 & 40,0 & 1017 & 49,0 & 563 & 51,0 & 454 & 46,0 \\
\hline Totales & 408 & 100,0 & 2.089 & 100,0 & 1.108 & 100,0 & 981 & 100,0 \\
\hline
\end{tabular}

Fuente: Alcaldía Mayor de Tunja. Secretaría de la Mujer, Equidad de Género y Desarrollo Social. Estadísticas Programa Población víctima del conflicto armado, 2014. 


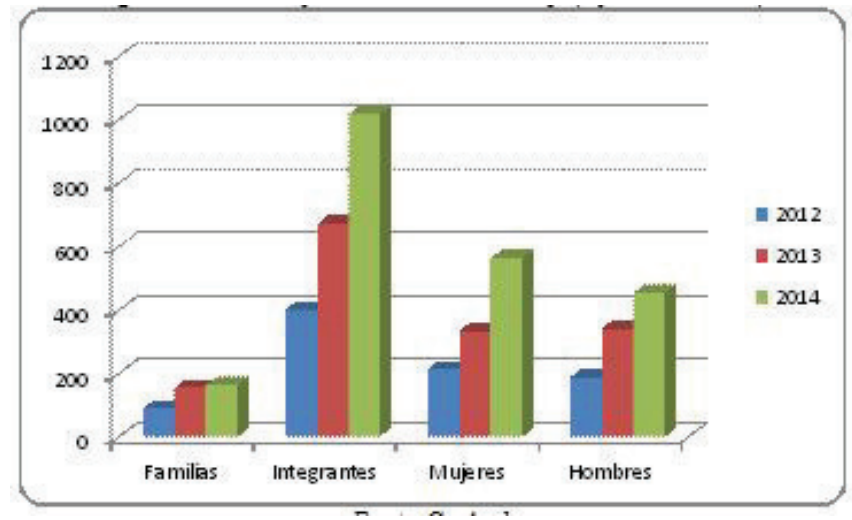

Figura 1. Familias desplazadas residentes en Tunja (sep., 2014).

Fuente: Tabla 1

Tabla 2. Caracterización población víctima del conflicto armado: distribución por edad (septiembre 2014)

\begin{tabular}{|l|c|c|c|c|c|c|c|c|}
\hline Rango edad / Año & $\mathbf{2 0 1 2}$ & $\mathbf{\%}$ & $\mathbf{2 0 1 3}$ & $\mathbf{\%}$ & $\mathbf{2 0 1 4}$ & $\mathbf{\%}$ & Totales & $\mathbf{\%}$ \\
\hline 0-5 : Primera infancia & 60 & 15.0 & 104 & 15,0 & 173 & 17,0 & 337 & 16,0 \\
6-12: Infancia & 83 & 21,0 & 47 & 7,0 & 160 & 16,0 & 290 & 14,0 \\
13-17 : Adolescente & 66 & 17,0 & 130 & 19,0 & 226 & 22,0 & 422 & 20,0 \\
18-26 : Juventud & 61 & 15,0 & 172 & 26,0 & 180 & 18,0 & 413 & 20,0 \\
27-60 : Adulto & 118 & 29,0 & 142 & 22,0 & 156 & 15,0 & 416 & 20,0 \\
+ 60: Adulto mayor & 12 & 3.0 & 77 & 11,0 & 122 & 12,0 & 211 & 10,0 \\
\hline Totales & 400 & 100,0 & 672 & 100,0 & 1.017 & 100,0 & 2.089 & 100,0 \\
\hline
\end{tabular}

Fuente: Alcaldía Mayor de Tunja. Secretaría de la Mujer, Equidad de Género y Desarrollo Social. Estadísticas Programa Población víctima del conflicto armado, 2014.

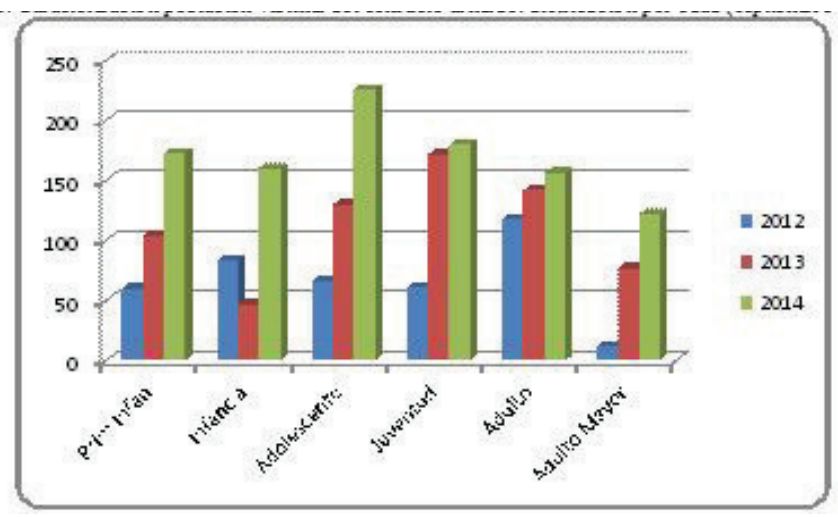

Figura 2. Caracterización población víctima del conflicto armado: distribución por edad (septiembre de 2014).

Fuente: Tabla 2 

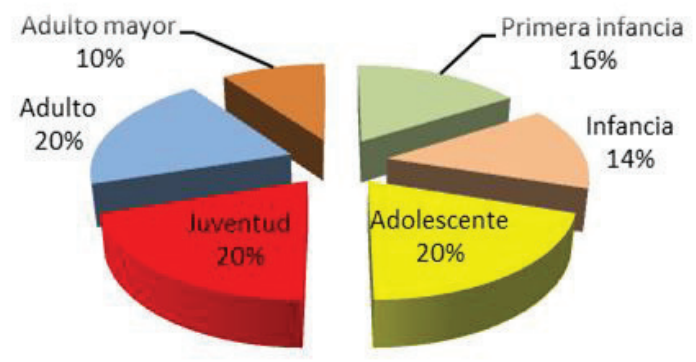

Figura 3. Distribución de los desplazados por edades

Fuente: Tabla 2

Tabla 3. Víctimas del desplazamiento en condición de discapacidad: distribución por género y grupo etéreo (septiembre 2014)

\begin{tabular}{|l|c|c|c|c|c|c|}
\hline Rango edad / Año & Mujeres & $\mathbf{\%}$ & Hombres & $\mathbf{\%}$ & Totales & \% \\
\hline 0-5 : Primera infancia & - & - & - & - & - & \\
6-12: Infancia & 1 & 1,0 & - & - & 1 & 1,0 \\
13-17 : Adolescente & 1 & 1,0 & - & - & 1 & 1,0 \\
18-26 : Juventud & 14 & 15,0 & 4 & 8,0 & 18 & 13,0 \\
27-60 : Adulto & 75 & 81,0 & 39 & 81,0 & 114 & 81,0 \\
+ 60: Adulto mayor & 2 & 2.0 & 5 & 11,0 & 141 & 100,0 \\
\hline Totales & 93 & 100,0 & 48 & 100,0 & 141 & 100,0 \\
\hline
\end{tabular}

Fuente: Alcaldía Mayor de Tunja. Secretaría de la Mujer, Equidad de Género y Desarrollo Social. Estadísticas Programa Población víctima del conflicto armado, 2014.

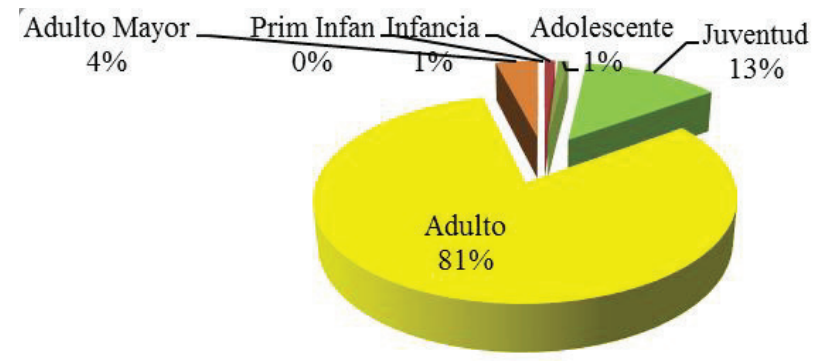

Figura 4. Desplazados en condición de discapacidad

Fuente: Tabla 3 
En cuanto a la procedencia de la población por zona y departamento en el año 2012, es la siguiente: a) Centro: Santanderes, Antioquia, Cundinamarca, Huila, Tolima, Caldas, Risaralda, Boyacá y Quindío y b) Llanos orientales: Meta, Vichada, Guainía, Casanare y Arauca. Para el 2013, se mantiene el comportamiento similar, respecto a las dos zonas y departamentos citados y se adiciona: a) Amazonas: Putumayo, Caquetá y Vaupés; b) Pacífico: Nariño, Valle, Cauca y Chocó; c) Caribe: Sucre, Córdoba, Atlántico, Bolívar, Magdalena y Guajira.

Por último, el 2014 mantiene la misma procedencia de zonas y departamentos del 2012; sin embargo, como se expresó anteriormente, el número tanto de familias como de integrantes de las mismas se ha incrementado, porque esta es una población que continúa recibiendo amenazas en los diversos municipios donde se han ubicado, razón por la cual migran hacia otro y así sucesivamente. Entre los entrevistados, algunos Ilevan más de diez año desplazándose por todo el país, especialmente en capitales de departamentos, porque existe la creencia que si allí se focaliza y caracteriza, van a recibir beneficios de diversa índole en forma inmediata, lo que no es cierto, porque en todo el territorio debe surtirse todo un proceso. En cuanto a los barrios donde residen en Tunja, la Secretaría de la Mujer afirma que en Ciudad Jardín, Trinidad, Libertador, San Francisco, El Carmen y Curubal, mientras que la Personería de Tunja aduce que además de los anteriores, están ubicados en El Dorado, Fuente, Jordán, Mirador, Bello Horizonte, Asís, San Ignacio, Perla, Joaquín Camacho, San Rafael, Nazareth, Sol de Oriente, Santa Ana, Santa Rita, Obrero, Triunfo, 20 de Julio, Kennedy, Milagro, Américas, San Lázaro, Las Peñitas, Patriotas, Santiago de Tunja, Altamira, Cooservicios. Respecto a la migración entre barrios, esta es continua porque se vive en permanente zozobra por la persecución a la que son sometidos, que se origina en los victimarios $y$, por otra parte, ante la falta de aceptación de la comunidad a donde llegan cuando se enteran que son desplazados, porque son calificados de delincuentes o de paramilitares.

En cuanto a la caracterización de los desplazados, según el artículo 3 de la Ley 1448 de 2011, cada víctima debe presentar ante el Ministerio Público (Procuraduría Regional, Provincial, Defensoría del Pueblo, Personería Municipal), la solicitud de registro como lo establece el artículo 155 de esta ley y los artículos 27 y 35 del Decreto Reglamentario 4800 de 2011. Después de diligenciada la declaración (formato único de declaración para la solicitud de inscripción en el registro único de víctimas), este se envía a la Unidad para la Atención y Reparación a las Víctimas, que es la entidad encargada del proceso de valoración (artículo 35 de la Ley 14448 de 2011), y determina la inclusión o no en el Registro Único de Víctimas (RUV). Por lo que no toda la población que se acerca a declarar ante el Ministerio Público, es reconocida como víctima según el artículo 3 de la ley mencionada. Es así que la entidad responsable de administrar la base de datos del RUV es la Unidad para la 
Atención y Reparación a las Víctimas, datos que son manejados con confidencialidad y reserva.

Frente al proceso de caracterización, esta responsabilidad recae en las entidades territoriales, con el fin de diseñar, adoptar y formular el Plan de Atención Territorial (PAT), mediante el cual se busca identificar la situación de la población víctima desde el punto de vista de las necesidades específicas y elementos particulares para la implementación de programas, proyectos y acciones que conlleven la garantía del goce efectivo de derechos a través de la prevención, atención, asistencia y reparación integral. Al respecto, cuando un desplazado llega a una ciudad, es deber del ente territorial correspondiente focalizarlo (ubicarlo) y caracterizarlo (determinar cuántos son, datos de procedencia, edad, género y qué necesitan). Un problema generalizado de los desplazados, es que llevan varios años, algunos hasta quince, migrando de ciudad en ciudad, porque siguen siendo amenazados, razón por la que al primer municipio a donde llegaron se les caracterizó y no pueden volverlo a hacer porque pierden la condición de desplazados.

En el año de 2013, el Ministerio de Vivienda aprobó el proyecto de Vivienda Antonia Santos, para el municipio de Tunja, tendiente a otorgar subsidio Familiar $100,0 \%$ de vivienda en especie, mediante entrega de 792 unidades habitacionales, para la población vulnerable residente en la ciudad. Es así como mediante acta del 21 de junio de 2013, el Fondo Nacional de Vivienda -en adelante Fonvivienda- y el municipio de Tunja, determinaron el porcentaje de adjudicación para el proyecto de la referencia así: a) Red Unidos 564 soluciones de vivienda equivalentes a un71,21\%; b) víctimas del desplazamiento forzado a causa del conflicto armado, 150 soluciones de vivienda, cuya participación es del 18,94\% y c) damnificados de ola invernal, 78 viviendas que corresponden al 9,85\% restante.

Posteriormente, el Departamento para la Prosperidad Social -en adelante DPS-, profirió la Resolución 0666 de 2012, mediante la cual se identificaron los potenciales beneficiarios de los subsidios. Con este soporte se realizó la identificación de potenciales beneficiarios, utilizando las bases de datos certificadas y remitidas por la Agencia Nacional para la Superación de la Pobreza Extrema (ANSPE) y de la Unidad de Atención y Reparación a las Víctimas del Conflicto Armado (UARIV), para el caso de Red Unidos y para Hogares Víctimas del Desplazamiento Forzado, respectivamente, el cual debería efectuarse con corte a febrero de 2013.

Al respecto, los listados fueron publicados en la Alcaldía de Tunja desde el 26 de julio de 2013, de conformidad con las exigencias de la convocatoria para presentar postulaciones, a través de la Resolución 454 de Fonvivienda. Sin embargo, la mayoría de las familias víctimas del desplazamiento forzado residentes en Tunja, no estaban incluidas en el listado de esta última publicación. Ante las mencionadas 
y graves diferencias, se advirtió que los listados contenidos en la Resolución 0666 de 2012, correspondientes a la población víctima del desplazamiento forzado, no coincidían con la realidad mostrada por la caracterización realizada por la Administración Municipal, a través de la Secretaría de Protección Social de Tunja.

Cabe anotar que al consultar por internet en la Red Nacional de Información (RNI) al servicio de las víctimas, el documento titulado «Reporte caracterización del conflicto armado Boyacá Tunja» ( $1^{\circ}$ febrero de 2015$)$, en las solicitudes recibidas por estas entidades del Formato Único de Declaración (FUD), Defensoría (359), Personería (384) y Procuraduría (25), hay registradas 768 solicitudes de desplazados en esta ciudad. No obstante, la única entidad de las citadas que ha recibido declaraciones en la vigencia 2012 a 2014, es la segunda; razón por la cual no se entiende el monto de las cifras presentadas. Existe una ambivalencia y es que el informe anterior en su parte final se refiere a Boyacá-Tunja, lo que permite suponer que están incluidas declaraciones obtenidas en otros municipios como Duitama, Sogamoso y Chiquinquirá, donde la focalización la realizan entidades como la Defensoría y la Procuraduría.

En cuanto a la gestión de solicitudes, aparece un total de 659 de las anteriormente citadas, incluyendo en la valoración a 495, labor que ha realizado el Estado y como no incluidas 158, valores parciales que no cuadran en la sumatoria. Lo que se observa es que las cifras de la RNI, no están actualizadas, mientras que las que existen en la Secretaría de la Mujer de Tunja, se depuran mediante visitas permanentes a las familias desplazadas para verificar sus datos, su condición y los requerimientos que tienen en diversos aspectos.

Al realizar las visitas periódicas se ha comprobado que muchos de los desplazados ya no están radicados en la ciudad de Tunja; en otros, como en el caso de algunos empleados de la firma Solarte y Solarte, mientras ellos se ocupaban en las labores para las que fueron contratados, sus compañeras o esposas intentaban hacerse pasar como desplazadas, lo que se ha controlado con la verificación de datos y confrontación con la realidad en que viven.

Respecto a las obligaciones contenidas en la Ley 1448 de 2011 y en los planes municipal de atención a víctimas (PAT) y de desarrollo, que al respecto tiene el municipio de Tunja, desde el año 2012 se ha venido adelantando la caracterización de la población desplazada víctima del conflicto armado, que reside en esta ciudad, donde los funcionarios encargados de adelantar esta tarea, observaron que las estadísticas existentes en la localidad diferían totalmente de las contenidas en la Resolución 0666 de 2012 proveniente de Fonvivienda. Esto Ilevó a investigar las razones de estas diferencias abismales, las cuales se justificaron porque en esta entidad no se tuvo en cuenta la caracterización realizada por la Secretaría de 
Protección Social de Tunja, sino la información contenida de la caracterización del año 2007.

Posteriormente, mediante Resolución 454 de 2013, el Ministerio de Vivienda ordenó la postulación de hogares ante la Caja de Compensación Familiar de Boyacá (Comfaboy), y para el 26 de julio de 2013 abrió la convocatoria para el caso de víctimas de desplazamiento forzado, teniendo en cuenta que el Ministerio de Vivienda había asignado para el período 2014-2015 792 viviendas de las 100.000 viviendas gratuitas aprobadas por la nación, las que serían asignadas y distribuidas para la Red Unidos (564), población víctima del conflicto armado (150) y para afectados por la ola invernal (78).

De los 150 cupos que inicialmente se destinaron para las familias víctimas del desplazamiento forzado, solo se postularon 51, porque estaba reducida y limitada para los hogares incluidos en los listados de focalización determinados por el DPS, remitidos a Comfaboy, y ello se justificaba según ellos, porque no tuvieron en cuenta los listados actualizados entregados por el municipio de Tunja con corte a 2013, sino unos desactualizados a 2007. Al no estar incluido el número de hogares desplazados restantes en la Resolución 0666 de 2013, la entidad encargada de las convocatorias se negó a recibirles la correspondiente documentación.

Ante los hechos citados, en el año 2013, el alcalde mayor de la ciudad de Tunja realizó varios requerimientos por escrito al Ministerio de Vivienda, Ciudad y Territorio, con el fin de reconsiderar los listados de focalización de la población víctima del conflicto armado por desplazamiento, de conformidad con la información veraz y actualizada que se les había entregado oportunamente, porque evidenció que en el municipio residían familias víctimas del conflicto armado que tenían la necesidad de vivienda, que no estaban en los listados de focalización remitidos a Comfaboy y que, de paso, se incumplía el compromiso con ellos de asignarles 150 unidades y no 51 .

Por otra parte, las víctimas del conflicto armado al ver que no obtenían sino respuestas negativas, acudieron a la Personería Municipal, que a través de abogada especializada en derechos humanos, presentó solicitudes al Ministerio de Vivienda para aclarar estos inconvenientes, mediante derechos de petición calendados el 13 y 20 de agosto de 2013, en los que solicitan la modificación de los listados.

En ese orden de ideas, la Personería Municipal, al no obtener respuestas para brindarles una solución a las familias desplazadas, en el mes de mayo de 2014 convocó al Ministerio de Vivienda, al Departamento de la Prosperidad Social, a la Red Unidos, a la Unidad Nacional de Víctimas, a Fonvivienda, a Comfaboy, Alcaldía de Tunja y Ecovivienda, para que en sesión ampliada de la Mesa de Participación 
de Víctimas, se resolviera la problemática. Sin embargo, el Ministerio manifestó que no era su responsabilidad, puesto que la información la enviaba al DPS, y que este a su vez la recibió de la UARIV.

Ante las negativas, la Alcaldía de Tunja convocó a reunión con los delegados del Ministerio de Vivienda, Ciudad y Territorio; Ecovivienda, DPS, Unidad de Víctimas - Tunja, Personería Municipal y representantes de las víctimas del conflicto armado, en donde se acordó que: a) la Alcaldía de Tunja, enviaría la caracterización de la población víctima de desplazamiento forzado que reside en la ciudad de Tunja, a la Unidad de Víctimas con sede en esta ciudad, con el fin de depurar y filtrar los listados, compromiso que se cumplió a cabalidad y b) Una vez efectuada la depuración y filtro, la UARIV remitiría los resultados de la verificación al Departamento a la Prosperidad Social, con el fin de «estudiar la posibilidad de tener en cuenta a estas familias», para adjudicarles la totalidad de las soluciones de vivienda que inicialmente se habían dispuesto, es decir 150 cupos, de los cuales aún se encuentran sin asignar 99 subsidios para la población en condiciones de desplazamiento. La unidad local cumplió con el compromiso, sin embargo el DPS, nunca resolvió lo pertinente a las viviendas restantes.

A continuación, el día 11 de marzo de 2015, el Ministerio de Vivienda respondió el derecho de petición formulado por los representantes de la Mesa de Participación de Víctimas de la ciudad de Tunja, donde informó que en una mesa interna realizada el 31 de enero de 2015 en sus dependencias, se decidió modificar los porcentajes de asignación de los grupos poblacionales por la necesidad de asignar los 99 cupos para completar los beneficiarios del proyecto de vivienda Antonia Santos, teniendo en cuenta que en las tres convocatorias realizadas para población víctima del desplazamiento solo 51 cumplieron con los requisitos exigidos.

Teniendo en cuenta lo expuesto, el 26 de mayo de 2015 se llevó a cabo otra reunión con el representante de las víctimas, la gerente de Ecovivienda, la personera municipal y un delegado del Ministerio de Vivienda, funcionario que informó que al determinar el cambio del cupo del grupo poblacional, se procederá a programar el sorteo que está pendiente de realizar en el Proyecto Conjunto Residencial Antonia Santos, dirigido ahora a Red Unidos, aumentando en 99 el número de viviendas a $663(83,71 \%)$ y disminuyendo la asignación para la población víctima del conflicto armado a 51 viviendas (6.44\%). Hay que recordar que la participación inicial era de 18,93\% (150 viviendas). En este caso, si se otorgan 150 (37,0 \%) soluciones de vivienda al mismo número de familias víctimas del desplazamiento por el conflicto armado residentes en Tunja, de un total de 408, quedarían pendientes $258(63,0 \%)$.

Por otra parte, al ser negativas todas las respuestas dadas por las diversas instancias e instituciones para resolver la negación de los 99 cupos asignados en principio por 
el Ministerio de Vivienda a la Población Desplazada de Tunja, la Personería de Tunja instauró una acción de tutela el 10 de junio de 2015, la cual correspondió por reparto al Juzgado $9^{\circ}$ Administrativo de Tunja, cuyos apartes principales se relacionan a continuación.

En la Acción de Tutela 20150097, los demandados fueron: nación; Ministerio de Vivienda, Ciudad y Territorio; Fondo Nacional de Vivienda; Unidad de Atención y Reparación Integral de Víctimas; Departamento para la Prosperidad Social. En la contestación de la demanda, cada entidad expuso sus argumentos y eludió responsabilidades, cuestionando la impetración de la acción de tutela, porque no era el mecanismo idóneo para reclamar. Sin embargo, esos cuestionamientos fueron los argumentos que le dieron solidez al fallo de la misma.

En las respuestas dadas por los representantes de las entidades demandadas en la acción de tutela 2015-0097, se refleja uno de los múltiples problemas que enfrenta el Estado colombiano, porque la intervención de muchos sin que exista articulación y seriedad entre ellos conlleva resultados nefastos como los ocurridos con las 99 viviendas destinadas para la población desplazada residente en esta ciudad. En sus respuestas, todas eluden responsabilidades y se las endilgan a otra $u$ otras, sin embargo, quienes encabezan la violación de los derechos fundamentales de las familias afectadas son el Departamento para la Prosperidad Social, la Unidad de Víctimas, Fonvivienda y el municipio de Tunja, porque cada uno actúa por su cuenta, sin la colaboración que debe caracterizarlas para el logro de la eficiencia.

El caos anterior se generó no por la ausencia de familias desplazadas residentes en la ciudad de Tunja, sino por la desactualización de las bases de datos donde estaba la caracterización de las familias, que al cierre de la vigencia de 2014, eran de 408, en contra de las cifras de los censos tomados como referencia 2004-2007, totalmente desactualizados. Por otra parte, el Departamento de la Prosperidad Social, Fonvivienda y, sobre todo, el municipio de Tunja, no podían modificar abusiva y arbitrariamente los porcentajes de los componentes poblacionales, máxime cuando este último conocía de las diferencias abismales, la desactualización en la caracterización existente y porque no se garantizó una revalorización de los datos de las familias desplazadas.

Así mismo, el municipio en sus diversas instancias es testigo de la insistencia permanente de parte de los representantes de la Mesa de Víctimas de la población desplazada en Tunja y del acompañamiento continuo que realizó y realiza la Personería Municipal, que se ha convertido en testigo de las injusticias y defectos cometidos por las diferentes entidades. Entonces, no se concibe cómo el ente municipal se convierta en contradictor de los intereses de los desplazados, violando sus derechos fundamentales. 
Como respuesta a los derechos fundamentales vulnerados por las diversas entidades del Gobierno, el Juzgado Noveno Administrativo Oral del Circuito de Tunja, el 15 de junio de 2015, resolvió:

PRIMERO. Tutelar los derechos al debido proceso y a la vivienda digna de las familias en situación de desplazamiento de la ciudad de Tunja, posibles beneficiarios del Subsidio Familiar de Vivienda en Especie del proyecto «Antonia Santos» de la ciudad de Tunja».

SEGUNDO. Ordenar al Coordinador Regional Central de la Unidad de Atención y Reparación Integral de Víctimas, que envíe al Departamento para la Prosperidad Social el listado base de datos actualizados a 28 de febrero de 2013 contentiva de caracterización víctima de desplazamiento forzado reubicada en la ciudad de Tunja, previo el cruce correspondiente con sus registros y bases de datos que sean del caso, teniendo en cuenta las caracterizaciones enviadas por el Municipio de Tunja, actualizadas a 28 de febrero de 2013, en el término de 5 días hábiles. En caso de que las mismas no le hayan sido allegadas, las requerirá al Enlace Municipal de Víctimas de la Secretaría de la Mujer, Equidad de género y Desarrollo Social, quien las entregará en forma inmediata.

TERCERO. Ordenar al Director del Departamento para la Prosperidad Social que en el término de los 10 días siguientes al recibo de información por parte de la Unidad de Víctimas descrita en el numeral anterior, realice un reestudio de posibles beneficiarios del Subsidio Familiar de Vivienda en Especie (SFVE) para el conjunto residencial «Antonia Santos» de la ciudad de Tunja de los hogares en condición de víctimas de desplazamiento forzado teniendo en cuenta la información que se le allegue por parte de la Unidad de Víctimas, y en caso de verificar que deben incluirse nuevos beneficiarios en condiciones de desplazamiento de la ciudad de Tunja que cumplan con las condiciones y requisitos de asignación, procederá a modificar mediante acto administrativo, los componentes poblacionales y el listado definitivo de hogares beneficiarios del SFVE a efectos de que al listado existente se añadan nuevas familias beneficiarias y de esta forma completar el cupo de 150 subsidios asignados a dicha composición poblacional en forma inicial (18,93\% de porcentaje de composición poblacional). En caso de que se modifique lo anterior, el DPS comunicará a FONVIVIENDA, la resolución que contenga la relación de los hogares potencialmente beneficiarios para cada proyecto de vivienda, en los términos del art. 6 del Decreto 2164 de 2013.

CUARTO. Ordenar al representante legal de FONVIVIENDA que en forma inmediata suspenda el proceso de apertura a la convocatoria a los hogares potencialmente beneficiarios para su postulación, absteniéndose de modificar los componentes poblacionales inicialmente fijados en 18,93\% del grupo de 
desplazados por la violencia en el Municipio de Tunja hasta que no le sea remitida respuesta definitiva por parte del Departamento para la Prosperidad Social, de que habla el numeral.

QUINTO. Ordenar a los representantes de las organizaciones de desplazados ASOCIACIÓN DE DESPLAZADOS DE COLOMBA - ASOPODESCOL y ASOCIACIÓN DE DESPLAZADOS DE BOYACÁ - ADEBOY que en caso de que se adviertan casos puntuales de otorgamiento de subsidios a propietarios de otros inmuebles, no residentes en Tunja o beneficiarios de subsidios a los que se les haya otorgado el mismo en convocatorias anteriores, remitan los mismos al DPS y a FONVIVIENDA con el fin de que previa confrontación con bases de datos emanadas de IGAC y Superintendencia de Notariado y Registro, confrontación frente a beneficiarios de subsidios a los que se les haya otorgado el mismo en convocatorias anteriores, dichas entidades tomen las medidas pertinentes».

En el fallo de la referencia se comprobó que entre las entidades demandadas no existe articulación y por eso cada una de ellas actúa como rueda suelta en la solución de un problema tan difícil y complejo, como es el desplazamiento poblacional generado por la cruenta guerra que se vive en el país. Por otra parte, Ilama la atención un problema que se escucha a voces en el municipio de Tunja, como es la asignación sucesiva de vivienda a personas que ya la poseen, no solo una sino varias y con una facilidad le son asignadas otras, como lo denuncian en esta acción de tutela dos agremiaciones de desplazados. En estas situaciones está inmersa la mano siniestra de la clase política, porque quienes dirigen las diferentes entidades con carácter decisorio respecto a las viviendas para desplazados han sido nombrados bajo esa influencia, que perdura como lastre en el país y qué mejor en época preelectoral contar con un bocado jugoso como es el tener 99 viviendas para asignar, quitadas a los desplazados con argucias diversas para adjudicarlas a su conveniencia, a fin de fortalecer el caudal político y obtener mayores votos.

Así mismo, la delegación en las cajas de compensación familiar -como entes privados que tienen una misión tan importante como es la recepción de documentos para los postulados a los planes de vivienda-, no deja de ser incómoda en el caso de Tunja, cuando existen precedentes de intervención política plena y despilfarro de los recursos de los boyacenses a través de varias administraciones. A manera de ejemplo, el director actual, posesionado desde el 6 de diciembre de 2010, fue diputado a la Asamblea de Boyacá en el período 200-2003 y representante a la Cámara por corto tiempo, gracias a la oportunidad que le brindó Zamir Eduardo Silva Amín, político oriundo de Chiquinquirá, que mantiene sus huestes electorales vivas y, gracias a ello, obtiene participación en los cargos que se distribuyen a dedo en el país. 


\section{Conclusiones y recomendaciones}

\section{Conclusiones}

La población desplazada víctima del conflicto armado colombiano residente en el municipio de Tunja, está amparada por el derecho internacional humanitario, a través de siete principios $(1,2,3,45,8$ y 18), catalogados como documento compilatorio e interpretativo de obligaciones del Estado colombiano con el derecho internacional. Es así como se reúnen los derechos con los alcances que tienen las personas que se encuentran en situación de desplazamiento, por el conflicto armado colombiano, al igual que las obligaciones que les corresponden a las autoridades para protegerlos. Este resumen e interpretación de los principios fue elaborada por el representante especial del secretario general de las Naciones Unidas para el Desplazamiento Interno, con base en un estudio exhaustivo de las disposiciones jurídicas internacionales que amparan a este grupo poblacional. En ese orden de ideas, está la legislación nacional contenida en leyes (387 de 1997, 1448de 2011 y 1537 de 2012), resoluciones (502 de 2012 y 604 de 2012), decretos (250 y 4760 de 2005; 1921, 2045 y 2490 de 2012) y legislación local (Plan de Desarrollo del Municipio de Tunja 2012-2015), relacionados todos con el derecho a la vivienda digna de la población mencionada.

En cuanto a las políticas públicas aplicables al derecho fundamental a la vivienda digna para la población desplazada víctima del conflicto armado, se han elaborado siete documentos Conpes con ese fin (2804 de 1995: Programa Nacional de Atención Integral a la Población Desplazada por la Violencia; 2924 de 1997: Sobre el Sistema Nacional de Atención Integral a la Población Desplazada; 3057 de 1999: Plan de acción para la prevención y atención del desplazamiento forzado; 3115 de 2001: Distribución presupuestal sectorial para el cumplimiento del Conpes 3057: Plan de Acción para la Prevención y Atención del Desplazamiento Forzado; 3400 de 2005: Metas y priorización de recursos presupuestales para atender a la población desplazada por la violencia en Colombia; 3616 de 2009: Lineamientos de la política de generación de ingresos para la población en situación de pobreza extrema y/o desplazamiento y 3740 de 2013: Tiene como fin la consolidación para la consolidación de la Política de Vivienda establecida en el Plan Nacional de Desarrollo 2010-2014 «Prosperidad para Todos»). Al igual de lo que ocurre en múltiples dependencias del Estado, en este caso, del orden nacional pareciera que la existencia de siete Conpes aprobados en el período 1995-2013, fuesen suficientes para atender la creciente, difícil y grave problemática de la población desplazada y sus necesidades de vivienda, sin embargo, la dicotomía y multiplicidad de funciones repetitivas o encontradas hacen que el aparato estatal no sea funcional, lo que conlleva a cuestionar las acciones emprendidas hasta ahora como se observará en capítulos posteriores. 
En la ciudad de Tunja están radicadas aproximadamente 600 familias, de las cuales 408 están caracterizadas; se han asignado viviendas a 51, y las 99 restantes, autorizadas por el mismo Estado, en este momento están en un limbo jurídico, donde la acción de tutela 20150097 impetrada con el apoyo de la Personería de Tunja, fue fallada a favor en primera instancia. Los demandados fueron: nación; Ministerio de Vivienda, Ciudad y Territorio; Fondo Nacional de Vivienda; Unidad de Atención y Reparación Integral de Víctimas; Departamento para la Prosperidad Social. En la contestación de la demanda, cada entidad expuso sus argumentos y eludió responsabilidades, cuestionando la impetración de la acción de tutela, porque no era el mecanismo idóneo para reclamar, sin embargo, esos cuestionamientos fueron los argumentos que le dieron solidez al fallo de la misma. En las respuestas dadas por los representantes de las entidades demandadas en la acción de tutela 2015-0097, se refleja uno de los múltiples problemas que enfrenta el Estado colombiano, porque la intervención de muchos sin que exista articulación y seriedad entre ellos conlleva resultados nefastos, como los ocurridos con las 99 viviendas destinadas para la población desplazada residente en esta ciudad. En sus respuestas, todas eluden responsabilidades y se las endilgan a otra u otras, sin embargo, quienes encabezan la violación de los derechos fundamentales de las familias afectadas son el Departamento para la Prosperidad Social, la Unidad de Víctimas, Fonvivienda y el municipio de Tunja, porque cada una actúa por su cuenta, sin el engranaje existente que debe caracterizarlas para el logro de la eficiencia.

En el fallo de la referencia se comprobó que entre las entidades demandadas no existe articulación y por eso cada una de ellas actúa como rueda suelta en la solución de un problema tan difícil y complejo, como es el desplazamiento poblacional generado por la cruenta guerra que se vive en el país. Por otra parte, Ilama la atención un problema que es un secreto a voces en el municipio de Tunja, como es la asignación sucesiva de vivienda a personas que ya la poseen, no solo una sino varias y con una facilidad le son asignadas otras, como lo denuncian en esta acción de tutela dos agremiaciones de desplazados. En estas situaciones está inmersa la mano siniestra de la clase política, porque quienes dirigen las diferentes entidades con carácter decisorio respecto a las viviendas para desplazados han sido nombrados bajo esa influencia, que como lastre perdura en el país y que mejor en época preelectoral que contar con un bocado jugoso como es el tener 99 viviendas para asignar quitadas a los desplazados con argucias diversas para asignarlas a su conveniencia, a fin de fortalecer el caudal político y obtener mayores votos.

Esas personas que se encuentran en situación de desplazamiento gozan, según la Constitución Política de Colombia de 1991, de una especial protección, dada su condición de marginalidad, extrema vulnerabilidad, indefensión y debilidad manifiesta. Ello implica que el oólo hecho de ostentar dicha calidad las hace beneficiarias de todas las ayudas y subsidios ofrecidos por el Gobierno nacional, 
sin someterlos a trámites engorrosos, que se suman a los agravios que ya han tenido que padecer. En materia de desplazados por la violencia, el espectro de sus derechos fundamentales es más amplio debido a su situación, que como ya lo ha expresado la Corte Constitucional,

han sido víctimas de diversas violaciones a sus derechos humanos, partir de hechos violentos, causantes de un desarraigo, que ven como la efectividad de sus derechos constitucionales continúa amenazada, debido a los obstáculos que deben superar para acceder a los servicios estatales desde una posición marginal, al punto que su situación de hecho es incompatible con el régimen constitucional... (Sentencia T-787 de 2008).

Por otra parte, la existencia de subgrupos dentro de los desplazados, como personas de la tercera edad, madres cabeza de familia, niños y las personas discapacitadas, implica una protección adicional a la reforzada (Corte Constitucional Sentencia T585 de 2006). Desde el año 1980, es tan crítica la situación de los desplazados por el conflicto armado en Colombia, donde cada vez es mayor el número, pero el Estado, en vez de destinar el presupuesto suficiente para atenderlos, crea entidades demagógicas que no están articuladas para prestar un servicio con eficiencia, razón por la cual la Corte Constitucional se vio forzada, en la sentencia T-025 de 2004, a declarar un estado de cosas inconstitucional en relación con la misma, en la que se obligó a las autoridades a ajustar sus actuaciones de manera tal que se logre concordancia entre el cumplimiento de los mandatos constitucionales, y en particular, la garantía de los derechos fundamentales de los desplazados, y las políticas y recursos destinados a esta finalidad.

A pesar de lo expuesto y de la multiplicidad de autos de seguimiento a la Sentencia T-025 de 2004, la situación de los desplazados en materia de otorgamiento de vivienda como derecho fundamental, en el caso de la población residente en Tunja, sigue siendo pésima por la forma tan burda como les raparon las 99 oportunidades de vivienda, al mismo número de familias y donde el municipio, es el gestor de este atropello. Retomando el expediente que dio origen a la sentencia de la referencia ( $T$ 653010), en él acumularon 108 expedientes más, que correspondían a acciones de tutela interpuestas por 1150 núcleos familiares, todos pertenecientes a la población desplazada, con un promedio de 4 personas por núcleo, y compuestas principalmente por mujeres cabezas de familia, personas de la tercera edad y menores, así como algunos indígenas.

La Sala Tercera de Revisión, de la Corte Constitucional, en este caso, concluye que la población desplazada enfrenta condiciones de vulnerabilidad extrema, donde la omisión reiterada por parte de todas las entidades se hace latente que se niegan a brindarles una protección eficaz y oportuna, violando diez de sus derechos 
fundamentales, incluyendo el de una vivienda digna, sin tener en cuenta que en estos grupos hay madres cabeza de familia, niños, adultos mayores y discapacitados.

En el caso anterior, y en el del grupo poblacional de desplazados de Tunja, se ha estado cometiendo una violación que es masiva, prolongada y reiterada (por acción u omisión), que se genera no solo por falta de voluntad política, sino porque todas las entidades, incluyendo a la Alcaldía local, carecen de articulación, estructura y principalmente de interés para solucionar este problema, lo que afecta las múltiples políticas que ha diseñado y aprobado el Estado, porque por una parte no hay suficiente presupuesto y porque obvian la responsabilidad que les compete ante un problema repetitivo que cada vez se acentúa más y donde el interés por la guerra y la barbarie, promovido por las clases dirigentes y países desarrollados que venden las armas, lleva a estos colombianos (más de 6.000 .000 a nivel nacional y 2.109 en Tunja), a un sinsentido.

El problema del desplazamiento forzado interno en Colombia, es tan preocupante para la Corte que Ilama a toda la sociedad, empresarios, Iglesia e industriales a unirse al Estado para solucionarlo, sin embargo, todos sin excepción han hecho oídos sordos y el monstruo se ha crecido a tales dimensiones, que ya no existen recursos suficientes para solucionarlo y se requiere de paso la ayuda internacional, no para que venda y comercialice armas con los insurgentes y con el Estado, sino para que haga aportes económicos y de estructura. La situación es tan delicada, que la Corte la cataloga como una tragedia nacional, que no solo afecta a los desplazados, sino a la sociedad, a las políticas del país y que tendrán gran incidencia hacia el futuro, ello se puede observar si se hace una mirada retrospectiva hacia la década del 80 , hace 35 años.

Llama la atención los términos que utiliza la Corte en algunos de sus apartados, donde es reiterativa al hablar de exclusión, y el autor le adicionaría falta de humanismo con distorsión de la realidad, porque se está frente a dos tipos de Colombia: Ia que no es desplazada y la desplazada. En la primera, se ubican todos los estratos donde, a su vez, está esa minoría que es la que decide los destinos del país, que es propietaria de la mayoría de la riqueza, de los cargos más remunerados, que a la vez decide la continuidad de la guerra, de la que obtienen grandes dividendos, porque se lucran de la expropiación de tierras, y lógicamente del desplazamiento.

En ese orden de ideas y poniéndose el autor de este escrito en la misma situación de los desplazados afectados por el conflicto armado colombiano, al observar que asesinan a los vecinos, amigos, familiares, violan sus mujeres, destrozan a los muertos con motosierras o los tiran vivos a las fauces de caimanes en los criaderos, cualquier persona por muy valiente que sea sale corriendo con los demás miembros de su familia, escasamente con lo que tengan puesto y sin recursos, abandonándolo 
todo. Esa familia, al Ilegar a alguna población o municipio, y empezar a pedir limosna, recibe el primer rechazo de la misma sociedad de la cual ella hace parte porque es colombiana. Luego viene la parafernalia de acudir a una entidad del Estado para que la focalicen y caractericen, donde ocurre el siguiente repudio, porque al igual que la mayoría de fuerzas del Estado, «estos que llegaron son paracos». Al no tener con qué alimentarse, y lógicamente desconocer sus derechos fundamentales, ve a sus hijos aguantar hambre y ser repudiados vilmente, por unos congéneres que se precian de ser todos hijos de Dios, que promueven y proclaman la igualdad.

Por otra parte, la Iglesia, que debería ser el centro de recepción y acogida de estos hermanos que cayeron en desgracia, no por culpa de ellos, sino de un Estado apático y permisivo, se dedica en su prédica cotidiana a promover la humildad, la práctica del amor y la acogida del necesitado con el apoyo de múltiples parábolas; pero, en la realidad se dedican a atesorar, metalizando más su actuar y dejaron a un lado la misericordia y la piedad. Es por ello, que los jerarcas viven en lo que ellos mismos denominan palacios, argumentos y posición contradictorios a la situación de su fundador, Cristo, que dormía con una piedra como cabecera. Si el ser humano es débil, mucho más lo es el desplazado colombiano, máxime cuando como cabeza de familia está una mujer, que tiene a cargo niños menores de edad, ancianos y personas discapacitadas, con el agravante que se encuentran sin documentos de identidad, siendo esta una razón más para endilgarles el título de delincuentes.

Respecto a la situación de los desplazados por el conflicto armado colombiano, su situación no es la mejor frente a los demás que se encuentran en otras ciudades del país, porque para la mayoría de ellos, provenientes de climas cálidos, vivir en Tunja, con el frío que Ilega hasta los huesos, la indiferencia de las autoridades locales, el desgano de las entidades nacionales encargadas de brindarles mejores condiciones de vida y el rechazo de la comunidad a donde llegan, hace que ellos muestren un alto índice de migración entre barrios, lo que se agrava cuando sus desplazadores además de llevarlos a condiciones delicadas de indefensión, los siguen persiguiendo para asesinarlos junto con sus familias. Por otra parte, entre los derechos constitucionales fundamentales que resultan amenazados o vulnerados por las situaciones de desplazamiento forzoso, en la jurisprudencia de la Corte se retoma solo el de una vivienda digna, puesto que las familias afectadas como se expresó anteriormente, tuvieron que dejar todo lo material que les permitía vivir en condiciones adecuadas, pero al asumir su nueva condición obligatoria lo mínimo que necesitan es que se les brinde un techo, teniendo el debido acompañamiento y apoyo por parte del Estado, que es el mayor responsable de su situación.

En ese orden de ideas, la Corte Constitucional en la sentencia de la referencia hizo dieciséis Ilamados perentorios ordenando a todas las entidades del Estado, darle 
cumplimiento a las necesidades de los desplazados, en el término de 48 horas a un mes, que no habían sido atendidas y que condujeron a impetrar la acción de tutela por los 109 accionantes. Si se retoma el contenido de estos y se reemplaza el nombre de las entidades de esa época por las que están actualmente, el problema persiste con mayor gravedad, con la misma connotación en la ciudad de Tunja, porque la ley 1448 de 2011, centrada en la restitución de tierras, no aborda suficientemente el problema del desplazamiento. Por otra parte, entre las entidades que todavía subsisten están la Defensoría del Pueblo y la Procuraduría, pero su accionar está encaminado hacia otros propósitos, especialmente a hacerse visibles en los agasajos, inauguraciones y convites que hace la clase política, que a cumplir con la función para la cual fueron creadas. El procurador, por su parte, está más inmiscuido en las decisiones de tipo religioso y de orden burocrático que su labor misional y de sanción para quienes infringen la ley, haciendo parte de los aquelarres que se Ilevan a cabo en el Opus Dei y en promover persecuciones a todo los que hagan parte de los grupos de izquierda y a sus opositores.

Así como la Corte Constitucional, en su momento (año 2004) consideró que la respuesta del Estado a través de las entidades demandadas en la acción de tutela, presentaban graves deficiencias, las de la acción de tutela 2015-0097 son vagas, irresponsables, dilatorias y mentirosas, que elaboradas por funcionarios públicos ameritarían no una sino varias sanciones y hasta la destitución, porque en su posición dominante generan un mayor agravio y desesperanza en los desplazados, emulando a los graves hechos de barbarie que los obligaron a salir de sus hogares y entorno. En este caso, actúan como jueces, pues se atreven a cuestionar la acción impetrada porque, según ellos, carece de fundamento y de paso niegan la existencia de un perjuicio irremediable. Habría que imaginarse a estos funcionarios ejerciendo justicia, porque ya habrían implementado en la jurisprudencia la pena de muerte, a pesar de que esta se aplica en el país desde hace muchos años, por fuerzas del Estado, grupos al margen de la ley y por la clase dirigente, al tildar sin pruebas reales a los desplazados de colaboradores de alguno de los grupos que están en confrontación. Suficiente es con el rechazo que sufren en los diferentes barrios de Tunja, por su condición de colombianos desarraigados de sus familias, costumbres, terruño y especialmente de sus propiedades. En ese orden de ideas, es cierto que tanto ayer (2004), como hoy (2015), los derechos de los desplazados por el conflicto armado en Colombia siguen siendo vulnerados por todas las entidades responsables de su atención y defensa, no tanto por omisión sino más por acción y abuso, porque están acostumbrados a vivir como la sanguijuela, succionando el erario a través de los cargos directivos que ostentan y donde los recursos con que se les pagan su salarios, provienen más del colombiano común y corriente y no de la élite donde se encumbraron, por tanto son inanes y apáticos a brindar soluciones verdaderas. 
En ese orden de ideas, la vulneración de los derechos de los desplazados por la cruenta violencia que se vive en el país, especialmente en los territorios donde yace la mayor cantidad de riquezas, se origina porque se carece de una estructuración entre las entidades, que desconocen las normas y especialmente la jurisprudencia vigente, porque en el caso de Tunja, ninguno de los entes demandados se defendió con argumentos jurídicos, sino con respuestas nimias, demostrando la incapacidad y elusión de un Estado que no dimensiona el creciente problema que está presente, al cual se niega a responder en forma oportuna y eficaz. El cuello de botella más delicado está en la falta de presupuesto, porque el porcentaje con que este se incrementa anualmente es menor al de familias desplazadas, violando el principio 18. Así mismo existe otro inconveniente, porque el desplazamiento se asocia con la restitución de tierras y la mayor proporción de los recursos se destina a este fin, generando en cierta forma una exclusión de estas personas.

En relación con la sentencia T-025 de 2004, a la fecha el bloque de constitucionalidad se ha incrementado notoriamente, pero la falta de compromiso presupuestal se mantiene en mayores dimensiones, porque el número de desplazados supera la cifra de los seis millones. La invisibilización de la población desplazada no solo se mantiene por parte de la sociedad, sino también por las entidades del Estado, que a pesar de tenerla en cuenta en la agenda pública, siempre las formula dando prelación a otros problemas, como lo ocurrido con la Ley 1448 de 2011 (Ley de Víctimas y Restitución de Tierras), que se centra en el título citado y escasamente en la población desplazada. En cuanto a la situación actual de desplazamiento, el proceso por parte del Estado no ha mantenido regularidad ni alcanzado credibilidad que exige el derecho internacional humanitario y la Constitución Política de Colombia. Los resultados, en este caso, son exiguos. Los esfuerzos interinstitucionales se invisibilizan por la precaria atención de los funcionarios y la falta de compromiso a nivel directivo. La tan anhelada coordinación interinstitucional es ambigua y aleja cada vez más todas las instancias. La ayuda humanitaria es parcial y no se entrega con la regularidad y de conformidad con las necesidades poblacionales.

Respecto a la prevención del desplazamiento forzado, el Estado muestra su pequeñez al solucionarlo, porque debido al ambiente burocrático con que se toman las decisiones, los actores armados ilegales se han diversificado y multiplicado, engendrando monstruos para pacificar a los propietarios de tierra, gracias al interés de las empresas transnacionales. En ese orden de ideas y manteniéndose el problema de los desplazados con mayor intensidad, es imposible que la Corte Constitucional levante el estado de cosas institucional, ni siquiera territorialmente, porque la situación de los desplazados es cada vez más grave, puesto que el Estado por muchas normas y políticas que produzca no puede implementarlas, porque no cuantifica ni destina el verdadero presupuesto para el problema del desplazamiento, ya que siempre lo ata a otros problemas. 
A través de la jurisprudencia, especialmente de la Sentencia T025/2004, la población desplazada está exigiendo y reclamando sus derechos, constituyéndose en una herramienta fundamental apoyada en la acción de tutela. A pesar de ello, como está ocurriendo en el municipio de Tunja, las diversas entidades del Estado continúan actuando sin ninguna articulación y violando flagrantemente sus derechos fundamentales, porque los ejecutivos que las dirigen funcionan aisladamente a las políticas y normas del Estado. Con la aprobación de la ley 1448 de 2011, continúan los problemas para los desplazados por el deficiente ambiente de ejecución. Por otra parte, la eficiencia y funcionalidad de los jueces y de la Corte Constitucional contrasta con el nimio interés y voluntad política de parte del ejecutivo y el legislativo, que no adoptan políticas públicas con contenidos de eficacia para disminuir y solucionar el desplazamiento forzado. Así mismo, a pesar de la dimensión del problema del desplazamiento forzado en Colombia, ha sido imposible cuantificar realmente el número y porcentaje de población atendida, porque las bases de datos no están integradas ni actualizadas, debido a que la cantidad de familias afectadas es cada vez mayor y dado que el problema carece de políticas concretas y acciones presupuestales para enfrentarlo. Por otra parte, ante la falta de recursos, si el Estado sigue manteniendo el sistema de regresión tributaria que afecta más con el gravamen a las clases populares y medias, favoreciendo con exenciones a los que más poseen (empresarios, terratenientes e industriales), es imposible que siquiera a largo plazo solucione el problema del desplazamiento. Otra situación sería si al acabarse la guerra, se destina la mayoría de estos recursos para la atención de la población desplazada. En ese orden de ideas, ante el incumplimiento de la nutrida jurisprudencia queda la protesta social como una forma de presión, siempre y cuando no se reprima con fuerza pública, como actualmente se hace con los indígenas a los que el Estado en connivencia con empresas trasnacionales y empresarios les han arrebatado tierras que ancestralmente les pertenecían. Si en el país se protesta, se corre el riesgo de ser calificado de guerrillero y de paso terrorista, pero no se le califica de paramilitar, porque es una ofensa para los grupos creados y patrocinados por el expresidente Uribe.

Mientras exista la politización de las entidades del Estado, dependientes de padrinos políticos que por muchos años con sus familias y seguidores han esquilmado los recursos de los más necesitados, aunado a la rampante burocracia que prima en el país, a la lenta ejecución de los recursos y asesinato de líderes locales, seguiremos en el limbo de la desesperanza.

En los problemas descritos existe otro lastre y es la errada orientación de los programas hacia los desplazados, porque no hay articulación entre entidades y niveles del Estado (nacional, distrital, departamental, municipal). A estas familias no se les puede atender con políticas que solo se orienten hacia los pobres, ya que es posible que se genere más vulnerabilidad. Uno de los errores que se mantiene y 
que es recurrente, es la selección de beneficiarios para asignarles vivienda o tierras, donde la responsabilidad de los entes territoriales es bastante difusa y porque se carece de compromiso por parte de las autoridades locales, que tienen escaso personal para atenderlos.

Por último, se concluye que las políticas públicas y la normatividad vigentes en Colombia y en el municipio de Tunja, como herramientas que se orientan a garantizar los derechos humanos a los desplazados por el conflicto armado colombiano, les brindan una vivienda digna a los integrantes del núcleo bajo, pero son principios humanistas parciales, porque existe una disfuncionalidad entre las diversas entidades encargadas de esta misión tan importante y por otra parte, especialmente la Ley 1448 de 2011 y otras están atadas a otros problemas y situaciones afines a la violencia armada que vive el país y escasamente a la población desplazada, generando en cierta forma un ambiente de exclusión. Así mismo, la flagrante violación del derecho fundamental a una vivienda digna en la población desplazada residente en Tunja, incide negativamente en 357 familias, de las que hacen parte más de centenar y medio de personas con necesidades educativas especiales, porque sus expectativas se ven truncadas, al tener que esperar muchos años más para que ese derecho sea alcanzado, máxime cuando siguen llegando más desplazados a la ciudad, contra los que tienen que competir frente a un Estado que presupuestalmente es paquidérmico y retardatario.

\section{Recomendaciones}

Teniendo en cuenta lo expuesto en este artículo, creemos conveniente hacer las siguientes recomendaciones:

- Realizar un estudio serio y concienzudo por parte de la Universidad de los Andes y la Contraloría General de la República, sobre el número de familias desplazadas, integrantes, ubicación, edades y sexo, situación actual con las correspondientes necesidades.

- Que exista voluntad política, con el esfuerzo aunado de la sociedad civil y de los empresarios.

- Promover y llevar a cabo una coordinación interinstitucional en todos los niveles.

- Prevenir el desplazamiento forzado.

- Lograr la paz y que con recursos de la guerra se atiendan las necesidades de esta población.

- Formular planes, políticas y proyectos encaminados a una verdadera reinserción social con generación de ingresos para esta población.

- Actualizar y depurar en forma permanente las bases de datos. 


\section{Referencias}

Codhes. (2013). La crisis humanitaria en Colombia persiste. EI Pacífico en disputa. Bogotá: Usta.

Concejo Municipal de Tunja (2012, 21 de junio). Acuerdo Municipal No. 0005 de 2012 (junio 21). Por el cual se adopta el Plan de Desarrollo Municipal "Hechos de verdad". Por una Tunja más Humana, Segura y Sostenible 20122015.

Corte Constitucional. (1997). Sentencia T-227 de 1997.

Corte Constitucional. (2000). Sentencia SU-1150 de 2000.

Corte Constitucional. (2000). Sentencia T-1635/2000.

Corte Constitucional. (2001). Sentencia T-327 de 2001.

Corte Constitucional. (2001). Sentencia T-1346 de 2001.

Corte Constitucional. (2003). Sentencia T-669 de 2003.

Corte Constitucional. (2015, 17 de feb.). Principios rectores del desplazamiento forzado interno. Anexo 3. Sentencia T-025 de 2004.

Cristo, J. F. (2012). La guerra por las víctimas, lo que nunca se supo de la Ley. Bogotá: Ediciones Colombia.

Defensoría del Pueblo (2013). Informe de la Unidad para la Atención y Reparación Integral a las Víctimas. Bogotá: Defensoría.

Departamento Administrativo Nacional de Estadística. (2014). Encuesta de Indicadores de Goce Efectivo de Derechos. Bogotá: DANE.

Departamento Nacional de Planeación -DNP-. (2013, 24 de enero). Conpes 3740. Importancia estratégica del "Programa subsidio familiar de vivienda urbana en especie de Fonvivienda". Bogotá: DNP.

Departamento Nacional de Planeación -DNP- (2010). Plan Nacional de Desarrollo 2010 - 2014 "Prosperidad para todos". Bogotá: DNP.

Ibáñez, A. M. \& Moya, A. (2007). La población desplazada en Colombia: examen de sus condiciones socioeconómicas y análisis de las políticas actuales. Informe final presentado a la Misión para el diseño de una estrategia para la reducción de la pobreza y la desigualdad (MERPD). 
Juzgado Noveno Administrativo Oral del Circuito de Tunja. (2015). Acción de Tutela No. 2015-0097. Accionante: Personería Municipal de Tunja.

Ministerio de Vivienda. (2015, marzo). Convocatorias para desplazados. Bogotá: Minvivienda.

NRC \& IDMC (2014). Global Overview 2014, People Internally Displaced by Conflict and Violence. En: http://www.internal-displacement.org/ publications/2014/global-overview-2014-people-internally-displaced-byconflict-and-violence

Organización de las Naciones Unidas -ONU- (1997). Report on internally displaced persons, prepared by the representative of the Secretary-General on internally displaced persons, Mr. Francis Deng, in accordance with General Assembly resolution 52/130 of 12 December 1997 and Commission on Human Rights, Resolution 1999/47 of 27 April 1999. En Documento ONU - Asamblea General - A/54/409.

Organización de las Naciones Unidas -ONU-. (1998). Doc E/CN.4/1998/53/Add.2, 11 de febrero de 1998. Informe del Representante Especial del Secretario General de Naciones Unidas para el tema de los Desplazamientos Internos de Personas, Francis Deng.

Organización de las Naciones Unidas -ONU-. (1998). Consejo Económico y Social . Comisión de Derechos Humanos: Intensificación de la promoción y el fomento de los derechos humanos y las libertades fundamentales, en particular la cuestión del programa y los métodos de trabajo de la Comisión de Derechos Humanos, Éxodos en Masa y Personas Desplazadas. Informe del Representante del Secretario general, Francis M. Deng, presentado con arreglo a la resolución 1997/39 de la Comisión de Derechos Humanos. Adición. Principios Rectores de los Desplazamientos Internos. E/CN.4/1998/ 53/Add.2

Red Nacional de Información -RNI- de la Unidad para la Atención y Reparación Integral a las Víctimas -UARIV-. (s.f.). [Online] Recuperado de http:// bit. Iy/1nPzF34.

Corte Constitucional (1998). Resolución 1998/50, en la cual instó al Representante Especial del Secretario General para el Desplazamiento Interno a aplicar tales principios en sus contactos con diversos gobiernos y organizaciones. Ver:http://www.corteconstitucional.gov.co/T-025-04/Anexos/ ANEXO\%203.pdf 
Redacción Política. (2015, 21 de abril). En Colombia se necesitarían más de 500 años para acabar restitución de tierras. El Espectador. Recuperado de http:/ /www.elespectador.com/noticias/politica/colombia-se-necesitarian-mas-de500-anos-acabar-restitu-articulo-556232

Restrepo, M. (2012). La política de guerra como técnica del capital y del poder. UPTC: Salamandra.

Restrepo, M. (2012). Las regalías: herencia medieval. El Espectador. Recuperado de rebelión.org/colombia,2012.Periódicoeldiario.com/ opinión/ derechoshumanos/2012.

Reyes, A. (2012). Guerreros y campesinos, el despojo de la tierra en Colombia 1958-2010. Bogotá: FCE.

Sarmiento, L. (2012). Territorio, barbarie y paz. UPTC: Salamandra. 